stations, but Pacific Coast ticks were much more numerous in chaparral at Hopland than in grassland at Sierra Foothill in both years. The annual activity periods of adults of these two species span several seasons, particularly fall to spring, but the western black-legged tick usually reaches its greatest abundance in mid to late winter, while Pacific Coast tick populations normally peak in late winter to early spring. These tick species seem to have primarily one peak of activity annually, although the western black-legged tick may have a fall peak of variable height preceding a major winter/early spring peak. It is unclear whether the fall peaks observed for the western black-legged tick originated from different or the same cohorts of subadult ticks or merely from sampling differences due to variable climatic conditions.

The seasonal periods of activity of these two tick species on vegetation had not been determined systematically before. An earlier study of western black-legged ticks (primarily adults) on 71 Columbian blacktailed deer at Hopland found that more deer were infested in winter and spring than in summer or fall, but that tick abundance was actually greater in fall and winter. Tick abundance on deer in fall and winter did not differ significantly, but the prevalence of infestation was greater in winter $(100 \%$, $\mathrm{n}=12)$ than in fall $(56 \%, \mathrm{n}=18)$. It is not surprising that these results and my findings agree, since ticks collected with a drag represent the same host-seeking component of the population that infests deer moving through vegetation.

Knowledge of the seasonal activity of all parasitic stages (subadults and adults) of vector ticks is needed to identify periods of greatest risk of exposure to tick-borne agents. Although adults of the western black-legged and Pacific Coast ticks commonly infest people, recent collection records demonstrate that nymphs of these ticks bite humans more often than was realized previously. Moreover, spirochete-infection rates in nymphs of the western black-legged tick are sometimes comparable to those in adult ticks (usually about $1 \%$ to $2 \%$ ).

Besides the Lyme disease spirochete, the western black-legged tick has been found infected naturally with an unclassified rickettsia of the spotted fever group and the bacterial agent that causes tularemia, and it has been implicated as an occasional cause of tick paralysis in dogs. The Pacific Coast tick has been found infected naturally with Colorado tick fever virus, spotted fever group rickettsiae, the agents producing $Q$ fever and tularemia, and, more recently, the Lyme disease spirochete (although less frequently than the western black-legged tick). It also has been implicated as a cause of tick paralysis in cattle, deer, and ponies in California.

Robert S. Lane is Associate Professor, Department of Entomological Sciences, University of California, Berkeley. The author thanks Manfred Hoben, Robert J. Keiffer, Tony Wanzer, and Ken Whittaker, Hopland Field Station, and Tim A. Clark, Sierra Foothill Range Field Station, for collecting ticks; Nancy O'Ferrall, HFS, and Carol L. Hollingsworth, SFRFS, for weather data; and Esther Omi-Olsen and Stephen A. Manweiler, UC Berkeley, for help with data analyses and preparation of figures.

\title{
Eucalyptus shows unexpected cold tolerance
}

Janine K. Hasey $\square$ J.M.Connor

\begin{abstract}
Although some species of eucalyptus trees in an experimental plantation were damaged in a 1989 cold snap, several species and clones survived temperatures lower than previously thought to be tolerated. The trees are in a low-elevation Sierra foothill test planting used for studies assessing fuelwood growth rates.
\end{abstract}

Eucalyptus are fast-growing hardwood trees used in California for firewood, bio- mass, and pulpwood, but cold sensitivity is a major limitation determining where they can be grown successfully. Many species of this genus commonly planted in California are native to the subtropical regions of Australia and are sensitive to freezing temperatures. Eucalyptus plantings throughout California have suffered damage or have been killed because the species that was planted was not sufficiently cold-tolerant for the site.

One objective of a fuelwood test planting at the Sierra Foothill Range Field Station was to compare cold tolerances of selected eucalyptus species and clones at a low-ele- vation foothill site. In February 1989, an arctic cold front swept through northern California, giving us the unique opportunity to test the limits of reported minimum temperatures that certain eucalyptus species could tolerate.

Fuelwood plantation cultural practices, yield data, and growth characteristics at 3.5 years of age were presented in California $\mathrm{Ag}$ riculture, November-December 1988. Our purpose in this article is to report and illustrate comparative freeze damage, injury ratings, and short-term recovery of the eucalyptus trees in a foothill plantation.

\section{Methods}

In March 1984, six eucalyptus fuelwood species or clones were planted as seedlings in a randomized complete block design with four replications. Each replicated block contains 49 trees planted on 6- by 6foot spacings. A second plot, without replication, was planted for observation purposes in 1986 next to the main plot. It contains four clones also planted on 6-by 6-foot spacings. The elevation at the site is 575 feet with a $7 \%$ slope.

Air temperatures were measured atstandard weather stations on the field station at elevations similar to that of the plantation. Low temperatures measured were $14^{\circ} \mathrm{F}$ on the mornings of February 4 and 5, 1989, and $18^{\circ} \mathrm{F}$ on February 6. Fourteen hours of temperatures below $20^{\circ} \mathrm{F}$ occurred on February 4 , followed by 10 hours below $20^{\circ} \mathrm{F}$ the next day.

The species, clones, seed sources, and minimum temperatures below which severe freeze damage is expected are listed in table 1. Many factors influence the lowest temperature tolerated by a given species, including duration of the cold weather, the temperatures immediately preceding the cold snap, and physiological condition of the tree at the time of the freezing temperatures.

We used a freeze injury rating system with a six-point numerical scale, which was developed by University of California researchers following a severe freeze in northern and central California in 1972 (see table 2 footnotes). Injury was evaluated on two dates. The early rating on March 13,1989, assessed the initial extent of the cold injury. Damage was visually estimated for each species by block (replicate). During the late rating on July 28,1989 , each tree was examined separately for short-term recovery.

\section{Results}

Early evaluations of the 1984 plot showed substantial damage to the $\mathrm{C}-1$ clone and a lesser degree of damage to $E$. globulus (blue gum) (table2). By the time of the later evaluation, the $\mathrm{C}-1$ clone had made considerable recovery. The wide range in ratings within the species grown from seed (non-clones) is 

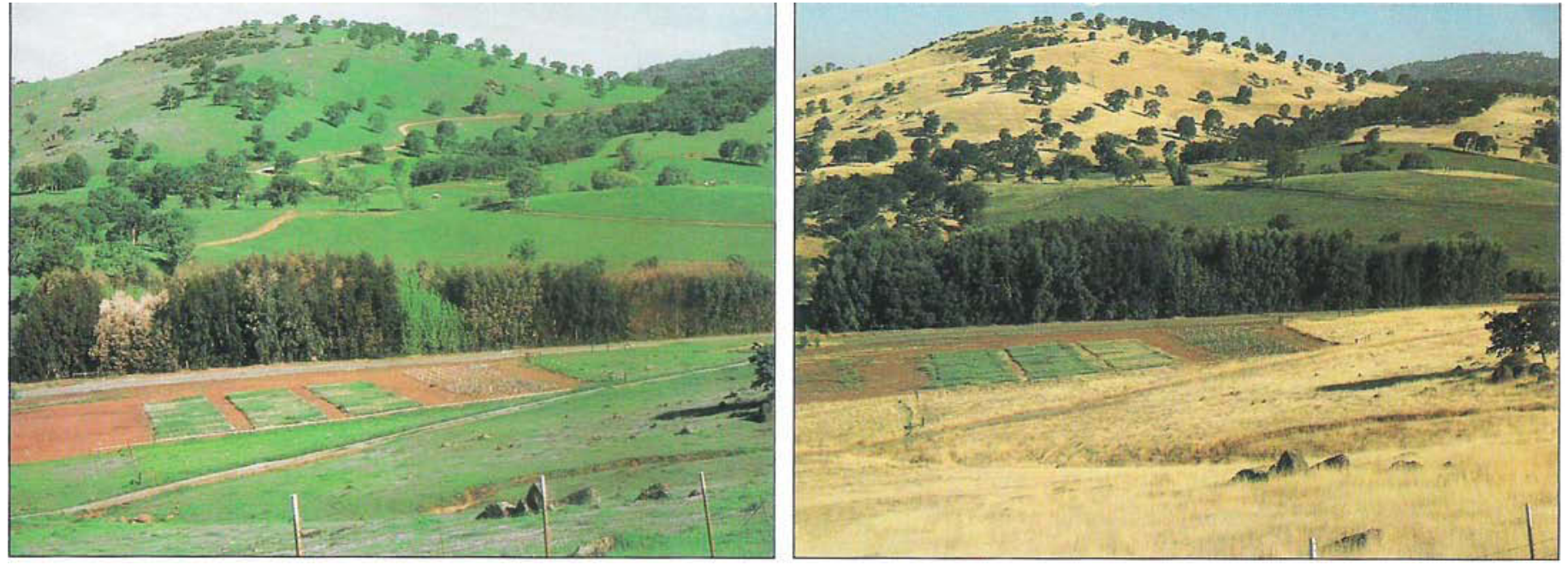

Fuelwood plots in May 1989 (above left) showed overall damage from a severe February freeze. In August 1989 (above right), after the late evaluation, trees had recovered.

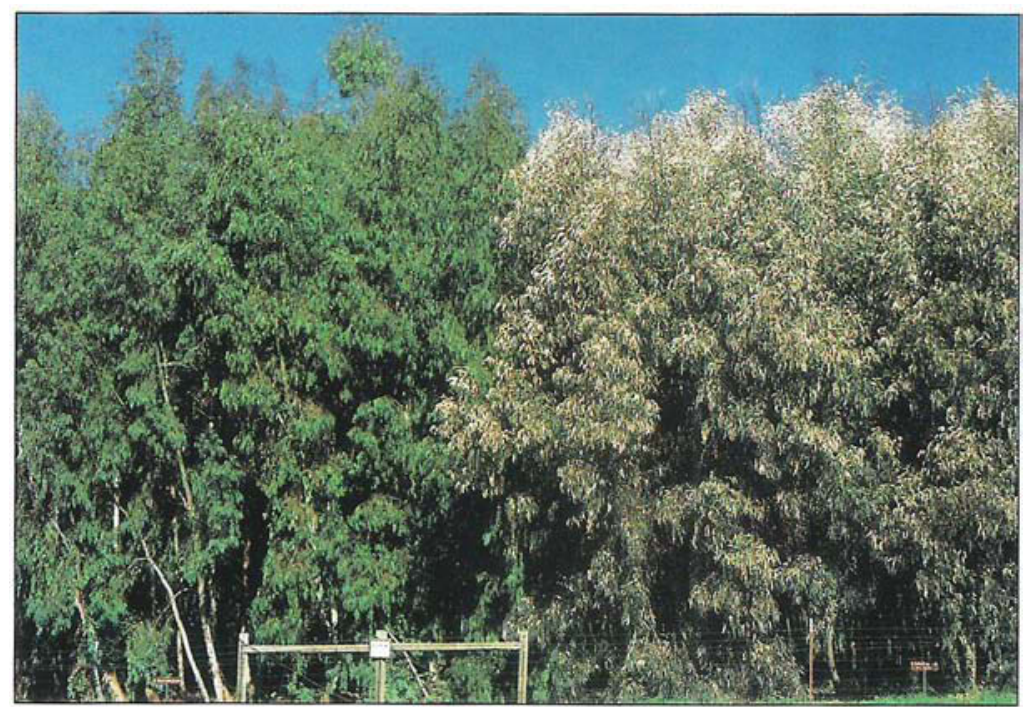

At the early evaluation in March 1989, injury was rated on a scale of 1 to 6 (no visible damage to above-ground plant dead; see table 2 footnotes). Eucalyptus dalrympleana at left in photo above was rated 1 , and the $C-1$ clone next to it was rated 4. At right, $E$. globulus was rated 3 ; freeze damage was especially variable among individual trees. Below left, the $\mathrm{C}-2$ clone had a 2 rating, compared with adjacent $E$. viminalis with a 1. Below right, severely injured $E$. grandis on left was rated 5 , next to $\mathrm{a}$ C-2 clone with a 2 .
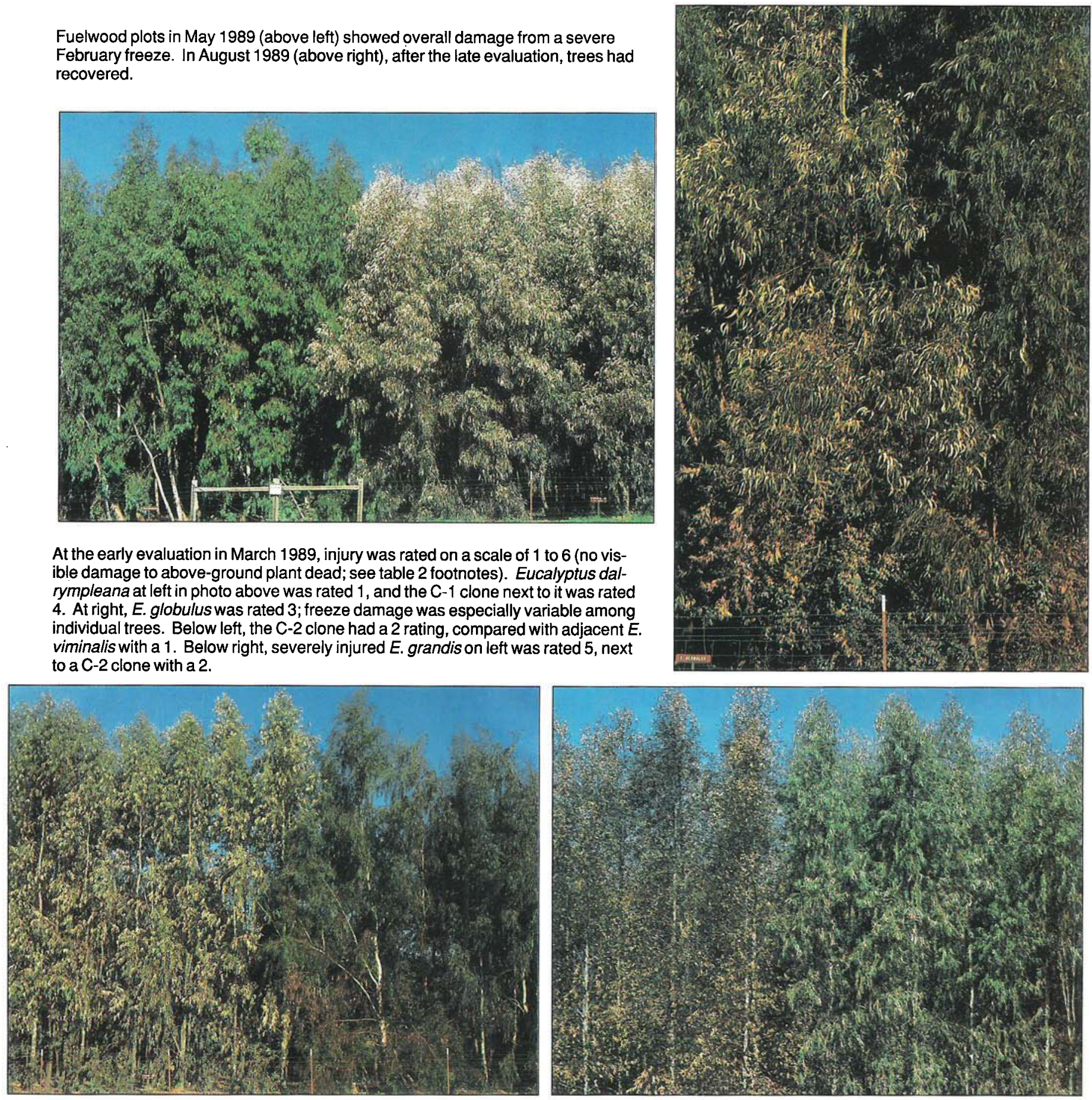


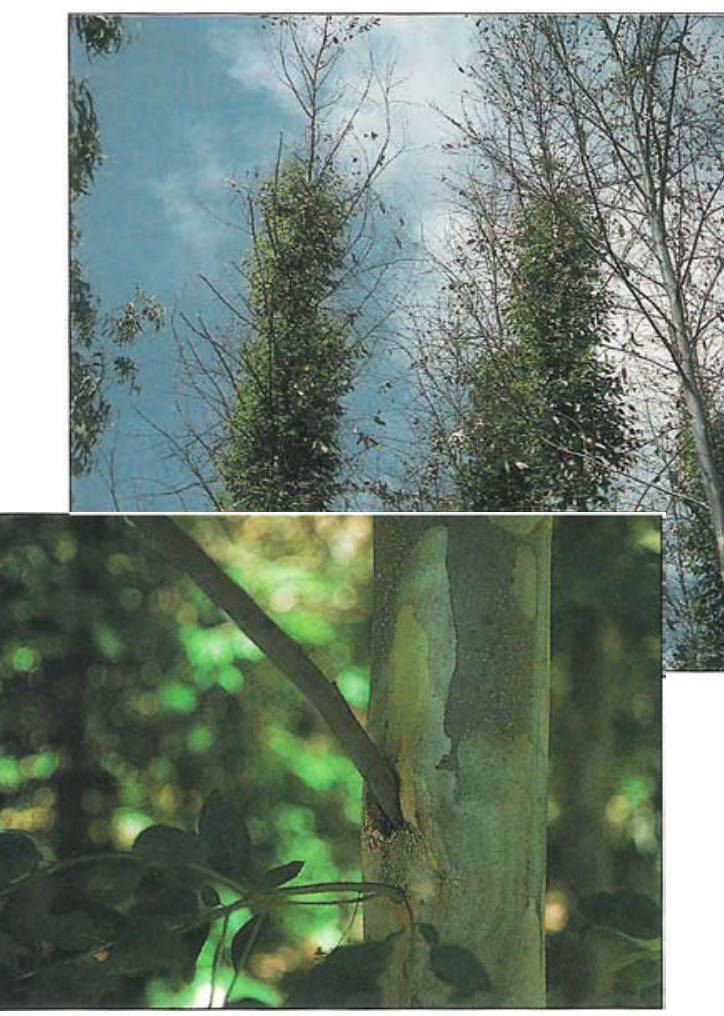

Recovery was seen at the late evaluation in July 1989: Eucalyptus grandis clones (above left) showed the trunk sprouting of a 4 rating (two trees in foreground were rated 5). In close-up at left, secondary bud on trunk has sprouted following death of primary branch. Some $E$. grandis showed basal sprouting only ( 5 rating, above right).

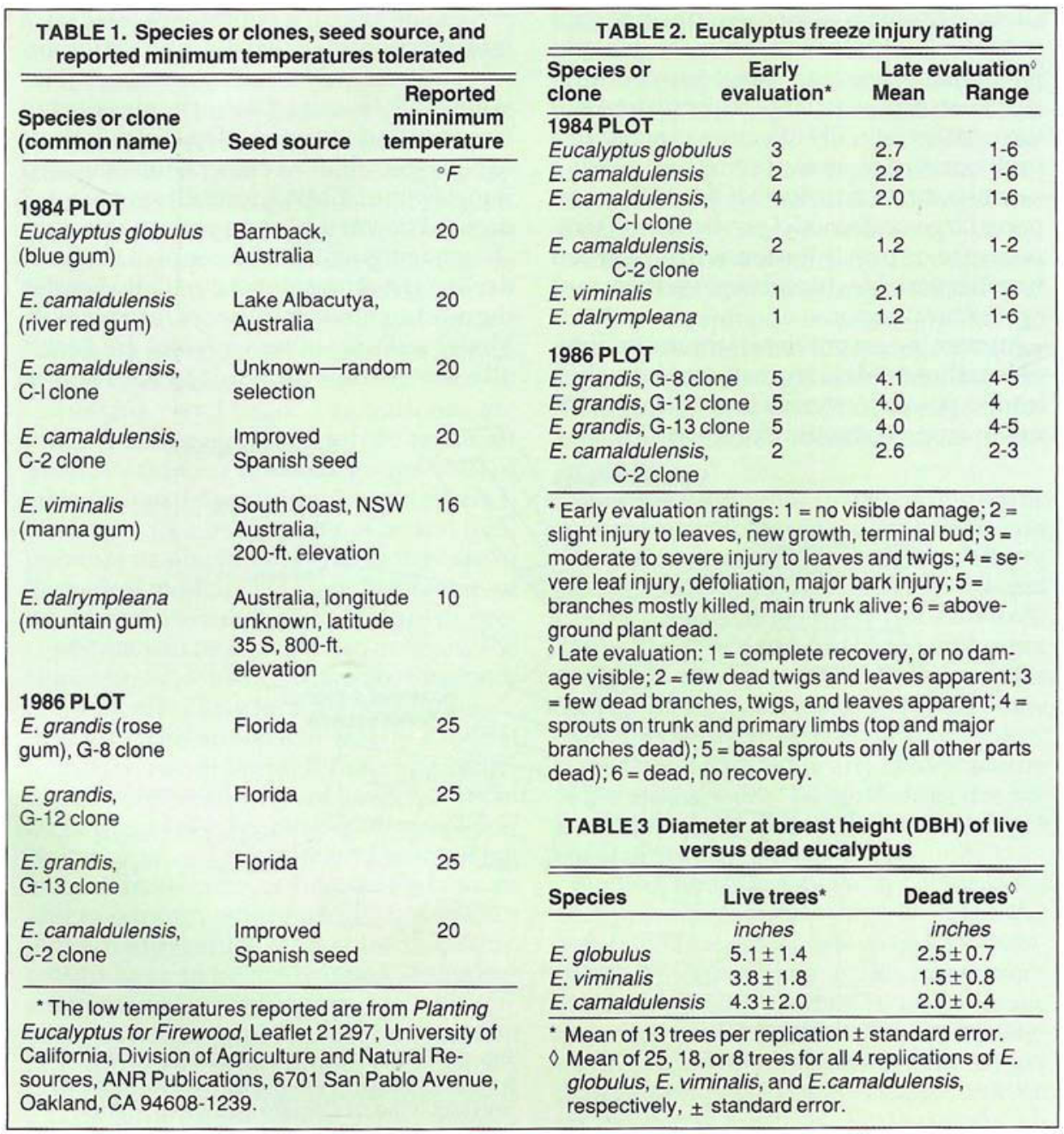

probably due to inherent genetic variability. Cold-tolerance variability was especially evident in E.globulus, E. viminalis (manna gum), and $E$. camaldulensis (river red gum). At the late evaluation, $25 \mathrm{E}$. globulus, $18 \mathrm{E}$. viminalis, 8 E. camaldulensis, and 2 E. dalrympleana (mountain gum) were dead (rating six). In contrast, no C-2 clones and only $2 \mathrm{C}-1$ clones were dead at that evaluation. The dead trees were the smaller individuals within a block (table 3 ).

In the 1986 observation plot, all three $E$. grandis (rose gum) clones showed severe damage at the early evaluation. The $\mathrm{C}-2$ clone had light damage, as in the older plot. Trunk or basal sprouts were evident on $E$. grandis clones by early June. By the late evaluation, trunk and basal sprouts had grown substantially.

\section{Conclusion}

The eucalyptus species at this site survived temperatures lower than the minimums previously reported for those other than E. dalrympleana. That species is reported to tolerate temperatures as low as $10^{\circ} \mathrm{F}$. Freeze damage was most severe on $E$. grandis. Annual measurements of diameter at breast height, tree height, and volume per acre will continue in an effort to determine optimum harvest time. As we accumulate data, we will attempt to learn whether freeze damage affected annual growth.

Janine K. Hasey is Farm Advisor, Cooperative Extension, Sutter-Yuba counties; and J.M. Connor is Superintendent, Sierra Foothill Range Field Station, Browns Valley. The authors are grateful to Don Springsteen and staff at the station for field assistance. 